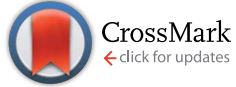

Cite this: RSC Adv., 2015, 5, 68493

Received 14th July 2015

Accepted 6th August 2015

DOI: $10.1039 / \mathrm{c} 5 \mathrm{ra} 13840 \mathrm{j}$

www.rsc.org/advances

\section{Hydrogenation of allyl alcohols catalyzed by aqueous palladium and platinum nanoparticles $\uparrow$}

\author{
Krystel Di Pietrantonio, ${ }^{a}$ Francesca Coccia,,$^{a}{ }^{a}$ Lucia Tonucci, ${ }^{\text {tb }}$ Nicola d'Alessandro ${ }^{a}$ \\ and Mario Bressan ${ }^{a}$
}

A series of Pd and Pt nanoparticles (NPs) was prepared starting from the corresponding metal ions and lignosulphonates; NPs were tested as catalysts for allyl alcohols hydrogenation in water at room temperature and pressure. All NPs were active with sharp differences in conversions and selectivities: Pt NPs formed mainly saturated alcohols, whereas Pd NPS were more active, but less selective, forming, in addition to saturated alcohols, also isomeric unsaturated alcohols and aldehydes, both saturated and unsaturated.

\section{Introduction}

Low molecular weight saturated alcohols are currently studied in order to replace, at least in part, traditional fuels, for their good miscibility with hydrocarbons, high energy content and low vapor pressure. ${ }^{\mathbf{1 , 2}}$ At present, for one of the most promising derivative, i.e. butyl alcohol, yields for the current biotechnological process and costs are far to be satisfactory. ${ }^{3-5}$ At the contrary, a useful building block for chemical and pharmaceutical processes, 1-propanol, ${ }^{6}$ could be obtained by hydrogenation of 2-propen-1-ol, which, in turn, can be produced by deoxydehydration of glycerol, a by-product of biodiesel production, available in large amounts and at relatively low costs. ${ }^{7-9}$

In general, the hydrogenation reactions have a crucial role in the preparation of required products for biorefinery and for the flavor, fragrance and pharmaceutical industries, ${ }^{\mathbf{1 0 - 1 5}}$ which are obtained from highly oxygenated biomasses by lowering their $\mathrm{O} / \mathrm{H}$ ratio. ${ }^{16}$ Hydrogenations are normally performed using hydrogen gas and heterogeneous metal catalysts, such as Raney® nickel or palladium, rhodium or platinum metals. ${ }^{17-20}$ The selectivity in the reduction of the $\mathrm{C}=\mathrm{C}$ group in the presence of other functional substituents (e.g., $\mathrm{C}=\mathrm{O}$ or $\mathrm{OH})$, can be controlled by a variety of parameters, such as the nature of the metal catalyst, the presence of a second metal (bimetallic catalysts), the size of metal particles and the nature of the supporting materials (electron-donating or -withdrawing ligand effects, metal-support interactions and solvent effect). ${ }^{\mathbf{2 1 - 2 6}}$

Metal nanoparticles (NPs) are becoming increasingly attractive for industrial catalysis, thanks to their high surface-

\footnotetext{
${ }^{a}$ Department of Engineering and Geology, G. d'Annunzio University of Chieti-Pescara, Italy

${ }^{b}$ Department of Philosophical, Educational and Economic Sciences, G. d'Annunzio University of Chieti-Pescara, Italy.E-mail: l.tonucci@unich.it; Tel: +3908713555340 $\dagger$ Electronic supplementary information (ESI) available: See DOI: 10.1039/c5ra13840j

\$ Present location: Department of Chemistry, University of Milan, Italy.
}

to-volume ratio, easy preparation and tunable dimensions. ${ }^{27,28}$ In particular, some palladium and platinum NPs are reported to be active catalysts in the hydrogenation of unsaturated hydrocarbons or allyl alcohols..$^{29-35}$ However, the preparation of metal NPs often involves the use of environmental unfriendly organic solvents. For this reasons, the principles of green chemistry prompted researchers to prepare new water "soluble" metal NPs, utilizing biochemical methods or, to prevent an extensive agglomeration, natural renewable stabilizers. ${ }^{36-41}$

In the present study, we investigated the hydrogenation of allyl alcohols catalyzed by Pt and Pd NPs, stabilized by lignins and prepared according to our previously published method. ${ }^{\mathbf{4 2 , 4 3}}$ To reduce and stabilize metal ions we used different types of lignin, an important and widely available waste-product of paper and sugar cane industries, which, at present, is mainly valorized for energetic uses. ${ }^{\mathbf{4 4 , 4 5}}$ In particular, we utilized kraft lignin, lignosulphonates and low-sugar lignosulphonates.

\section{Results and discussion}

We prepared a series of twelve NPs using two metals (Pt and Pd) and six water-soluble lignins: kraft lignin (KrLig), ammonium lignosulphonate (AmLig), calcium (CaLig) and sodium (NaLig) lignosulphonates and the corresponding low-sugar ones (CaROLig and NaROLig); lignins, in water solution and at $80^{\circ} \mathrm{C}$, acted as both reducing agents for the metal ions, i.e. $\mathrm{H}_{2} \mathrm{PtCl}_{6}$ and $\mathrm{PdCl}_{2}$, and as stabilizing agents for the formed nanoparticles. The formation of zero-valent NPs was signaled by the colour change of the solution (from brownish-yellow to brownblack, with no evidence for solid precipitates) and confirmed by UV-vis spectra (Fig. S1 and S2 $\dagger$ ); the integrity of the polymers was confirmed by ${ }^{1} \mathrm{H}$ NMR (Fig. S3-S6 $\dagger$ ) and IR spectra (Fig. S7-S9†). ${ }^{42}$ The NPs are stable, by UV-vis data, for 30 days at air and at $20{ }^{\circ} \mathrm{C}$.

TEM images were collected for all freshly prepared NPs (Fig. 1 and S10-S19†). As reported in Fig. 1, the Pd NPs are 

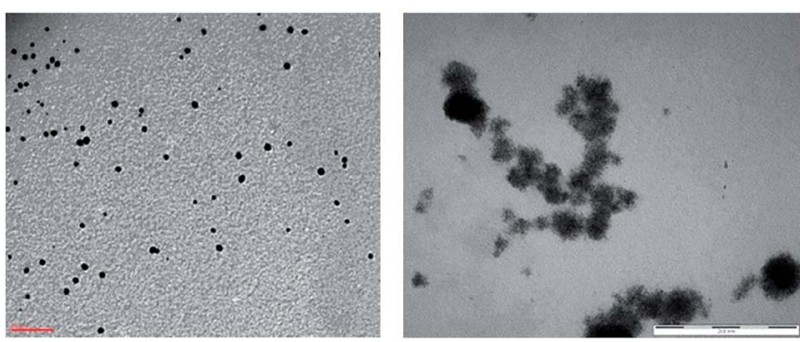

Fig. 1 TEM images of CaROLig Pd (left, scale bar $=100 \mathrm{~nm}$ ) and CaROLig Pt (right, scale bar $=200 \mathrm{~nm}$ ).

spherical while the Pt NPs are mostly irregular in shape and smaller than palladium ones.

In Table 1 the sizes of NPs are reported, as measured by TEM and DLS. For Pd NPs, the sizes obtained by TEM are always comparable with the results obtained from DLS spectra (except in the single case of AmLig NPs). For Pt NPs, TEM images did not allow accurate measurement of the particle size, because of their irregular shape and also because of the diffuse formation of clusters. Apparently, different lignins gave rise to nanoparticles with different sizes; in particular CaLig and NaLig NPs resulted invariably larger than nanoparticles obtained in presence of the corresponding low-sugar lignins, CaROLig and NaROLig. However, if one looks only to the largely spherical and regular Pd NPs, the measured diameters always fall in a relatively narrow range, $19.2 \mathrm{~nm} \pm 6.8$ (by TEM) and $15.8 \mathrm{~nm} \pm 7.5$ (by DLS), thus suggesting quite similar behaviours for the various lignins employed.

The XRD analysis of dried powders indicated a crystalline structure of all NPs and the peaks are identical to those previously reported for Pd and Pt zero-valent nanoparticles (Fig. S20 and S21 †). ${ }^{46,47}$

We conducted first the hydrogenation of 2-propen-1-ol by hydrogen gas at room pressure, in presence of the above Pd and Pt NPs, in water solution at $20{ }^{\circ} \mathrm{C}$. Then, to evaluate the behaviour of catalysts with increasing substitution at C-sp ${ }^{2}$ atom and the carbon chain extension, we performed the hydrogenation of substituted water-soluble allyl alcohols, i.e. 2-buten-1-ol, 3-methyl-2-buten-1-ol, cis-2-penten-1-ol, trans-2penten-1-ol. In presence of metal catalysts and hydrogen gas, several reactions are possible, i.e. $\mathrm{C}=\mathrm{C}$ reduction (Scheme 1 ,

Table 1 Sizes of Pt and Pd NPs

\begin{tabular}{lllr}
\hline & \multicolumn{2}{l}{ Diameter of M NPs $(\mathrm{nm})$} \\
\cline { 2 - 4 } & \multicolumn{2}{l}{ by TEM } & \multicolumn{1}{l}{ by DLS } \\
\cline { 2 - 4 } Lignin & $\mathrm{M}=\mathrm{Pd}$ & $\mathrm{M}=\mathrm{Pd}$ & $\mathrm{M}=\mathrm{Pt}$ \\
\hline NaROLig & 10 & 11 & 106 \\
KrLig & 12 & 9 & 5 \\
CaROLig & 15 & 17 & 31 \\
NaLig & 24 & 26 & 58 \\
CaLig & 26 & 27 & 132 \\
AmLig & 28 & 5 &
\end{tabular}

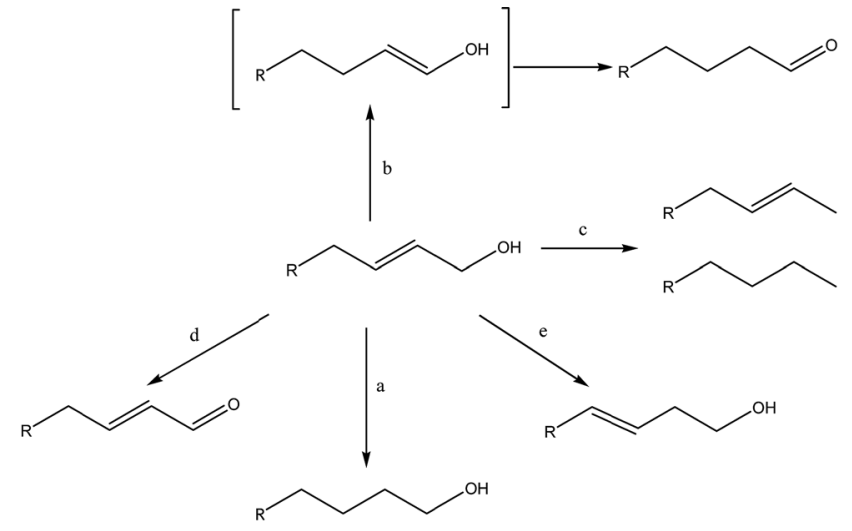

Scheme 1 Reactivity of an allyl alcohol in presence of $\mathrm{H}_{2}$ gas and metal catalysts.

reaction a), isomerization to saturated aldehydes (Scheme 1, reaction b), ${ }^{48-50}$ hydrodeoxygenation to hydrocarbons (Scheme 1, reaction c), ${ }^{51-53}$ oxidative dehydrogenation to unsaturated aldehydes (Scheme 1 , reaction $\mathrm{d})^{54-56}$ and isomerization by double-bond migration (Scheme 1 , reaction e)..$^{57,58}$

The catalytic activity of our NPs was tested in presence of 2-propen-1-ol (20 $\mathrm{mM})$ as the model substrate: the reactions were carried out for 24 hours in presence of $0.04 \mathrm{mmol} \mathrm{L}^{-1} \mathrm{Pd}$ NPs or $0.07 \mathrm{mmol} \mathrm{L}^{-1}$ Pt NPs and hydrogen gas at 1.013 barr in water. At preset time intervals we evaluated by ${ }^{1} \mathrm{H}$ NMR spectra the course of hydrogenation. The temperature of reaction was defined at $20{ }^{\circ} \mathrm{C}$; at $5{ }^{\circ} \mathrm{C}$ the reactions were definitely too slow, whereas at higher temperatures (i.e., $40{ }^{\circ} \mathrm{C}$ ) no better conversions and selectivities were obtained.

Alcohol conversions were definitely faster when Pd NPs were fluxed in water with $\mathrm{H}_{2}$ gas for 20 minutes, before adding the organic substrate. The above prolonged $\mathrm{H}_{2}$ flux had no effect in presence of Pt NPs. Finally, we performed the reactions in 100\% $\mathrm{D}_{2} \mathrm{O}$, but no incorporation of deuterium in the hydrogenated products was observed. In the absence of metal NPs, all substrates were quantitatively recovered unchanged, whereas, when the reactions were conducted in presence of $60 \mathrm{mg}$ of lignins, we observed small and erratic amounts of hydrogenation products, always below 5\% molar yield.

\section{Platinum catalysts}

During the hydrogenation of 2-propen-1-ol by Pt NPs, conversions were generally poor, below $40 \%$, apart the single case of $\mathrm{Pt}$ NaLig NPs, which exhibited almost quantitative conversion (Table 2).

Commercial $\mathrm{Pt} / \mathrm{C}$ gave, in the same reaction conditions, quantitative conversion of 2-propen-1-ol, leading to 1-propanol (70\%) and to significant amounts of the saturated aldehyde propanal. By contrast, in the reaction catalyzed by the Pt NPs, the only product found in the aqueous liquid phase was 1-propanol (even if with yields highly dependent upon the nature of the catalyst, from $10 \%$ to $60 \%$ ), with no evidence for the products of isomerization (propanal) or of oxidative dehydrogenation (propenal). Clearly, there was a serious gap 
Table 2 Hydrogenation of allyl alcohols by platinum catalysts ${ }^{a}$

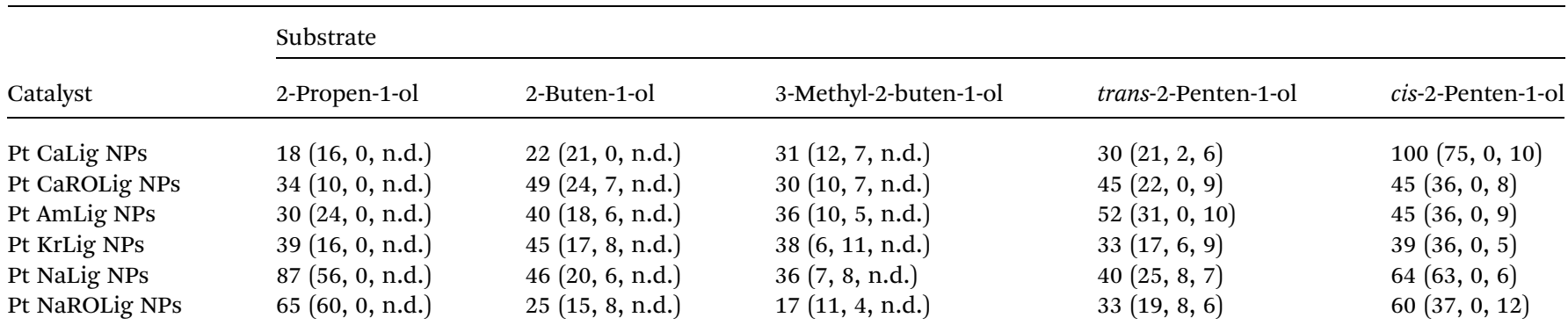

${ }^{a}$ Conversions, \% (yields, \%: saturated alcohol, 2-unsaturated aldehyde, alkane/alkene), at $24 \mathrm{~h}$. Reaction conditions, see Experimental. Data by ${ }^{1} \mathrm{H}$ NMR and GC. Values are mean of three replicates; percent errors are always $<10 \%$.

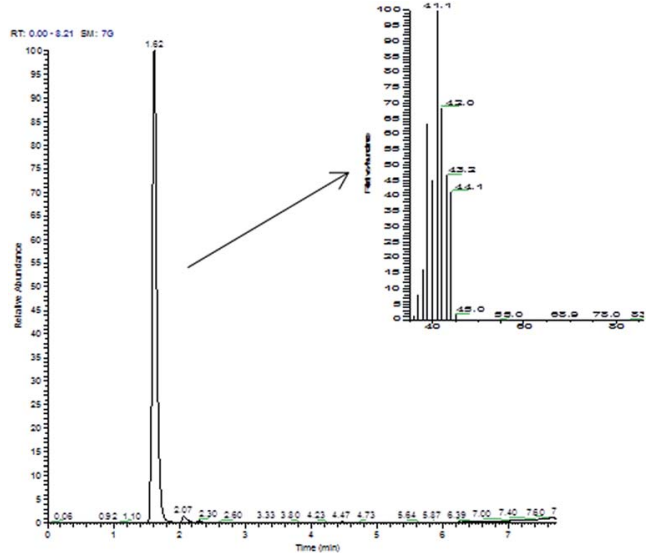

Fig. 2 Chromatogram and mass spectrum of headspace of 2-propen1-ol hydrogenation by Pt NaLig NPs.

between the amount of 1-propanol formed and the amount of 2-propen-1-ol reacted. In fact, when the headspace of the reaction vessels was analyzed by GC-MS, light hydrocarbons, i.e. propene $(\mathrm{m} / \mathrm{z} 42)$ and propane $(\mathrm{m} / \mathrm{z} 44)$, were detected (Fig. 2 ); to confirm this unexpected result, we synthesized deuterated 2-propen-1-ol- $\mathrm{d}_{5}$, which upon hydrogenation in the presence of

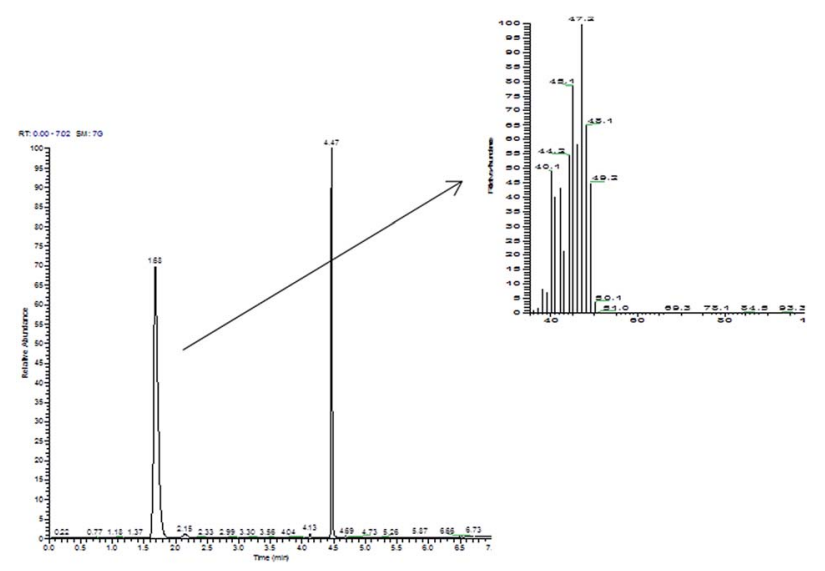

Fig. 3 Chromatogram and mass spectrum of headspace of 2-propen$1-0 l-d_{5}$ hydrogenation by Pt NaLig NPs. The signal at 4.47 is due to an impurity from the synthesis of 2-propen-1-ol- $d_{5}$.
Pt NaLig NPs gave rise to propene- $\mathrm{d}_{5}(\mathrm{~m} / \mathrm{z} 47)$ and propane- $\mathrm{d}_{5}$ $(\mathrm{m} / \mathrm{z} 49)$, detected by GC-MS in the headspace (Fig. 3).

It should also be noted that the reaction rate with Pt NPs (in particular with Pt NaROLig NPs), while comparable to that of $\mathrm{Pt} / \mathrm{C}$ within the first times of the reaction, significantly slowed down becoming practically zero in a few hours (Fig. 4). This strongly suggests a significant loss of activity during the reaction: indeed, TEM images showed important changes in the morphology of Pt NPs during the hydrogenation, the NPs underwent extensive aggregation to highly branched and irregular species, possibly responsible of the overall poor performance of the Pt nanocatalysts (Fig. 5).

Conversions of 2-buten-1-ol and 3-methyl-2-buten-1-ol (cis/trans mix) were again rather poor, always below 50\%, with very low yields in the corresponding saturated alcohols; moreover, and in contrast with 2-propen-1-ol, minor amounts of the oxidative dehydrogenation products, i.e. 2-butenal or 3-methyl2-butenal, were detected. Also in this cases, saturated aldehydes were never observed, whereas the corresponding light hydrocarbons, i.e. butane/2-butene or 2-methylbutane/ 2-methylbutene, were detected by the GC-MS of headspace, although no reliable quantification was possible.

Also trans-2-penten-1-ol was poorly transformed (30-52\%), the pivotal product being 1-pentanol, together with minor amounts of 2-pentenal (up to 8\%) and of the corresponding hydrocarbons pentane and/or pentene, which, in this case, could be reliably quantified by flushing the reaction mixtures

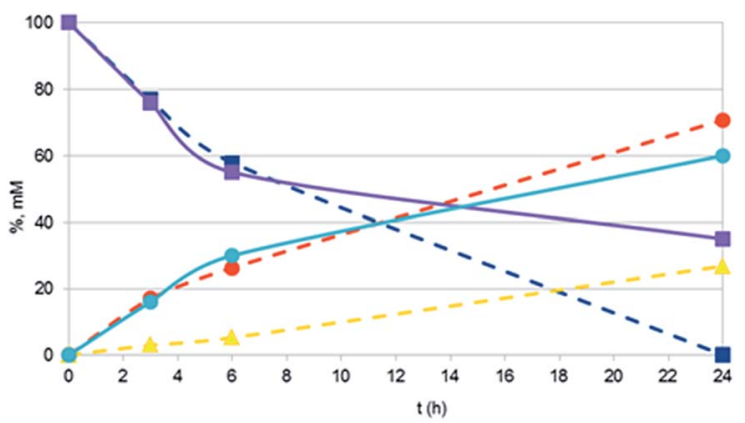

Fig. 4 Time course of 2-propen-1-ol hydrogenation by Pt/C (dashed lines) and Pt NaROLig NPs (solid lines): 2-propen-1-ol (squares); 1-propanol (circles); propanal (triangles). Reaction conditions, see Experimental. Data by ${ }^{1} \mathrm{H}$ NMR. 

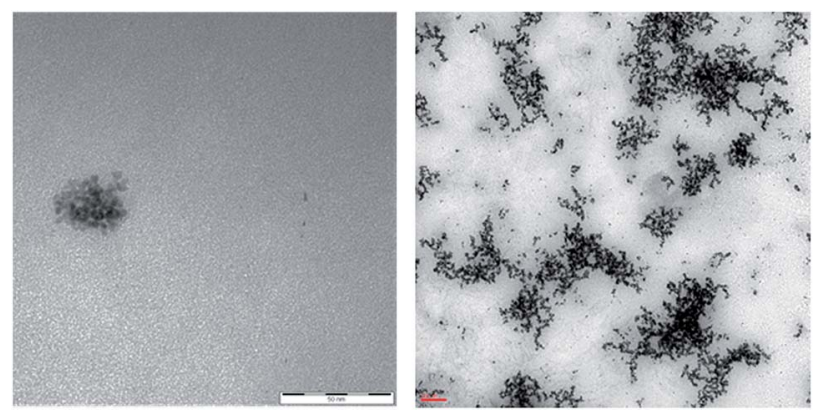

Fig. 5 TEM images of Pt AmLig NPs before (left, scale bar $=50 \mathrm{~nm}$ ) and after the hydrogenation reaction (right, scale bar $=100 \mathrm{~nm}$ ).

into a chloroform trap and then analyzing by GC. Mass balances could be satisfactorily closed in almost all experiments. Conversions of cis-2-penten-1-ol were definitely larger than those of the trans-isomer (between $39 \%$ and 100\%) and with 1-pentanol and pentane and/or pentene as the only products detected, with yields in 1-pentanol as high as $75 \%$. Moreover, 1-pentanol appears to favoured in the case of the cis-isomer, which strongly suggests a syn addition of hydrogen to the double bond, more sensitive to steric hindrance of the substituents (the same trend was observed also in the case of the Pd-catalyzed reactions, vide infra) Table 3.

\section{Palladium catalysts}

In presence of Pd NPs, conversions of 2-propen-1-ol were always quantitative (apart with Pd NaLig NPs; Table 3). However, the only products detected were always propanal (up to $74 \%$ ) and 1-propanol (up to 39\%), with no evidence for propenal or propane/propene. In all examined cases, mass balances were quite satisfactory.

Quantitative conversions and comparable yields of 1-propanol (29\%) and propanal (71\%) were also found in the reaction conducted in the same conditions with commercial Pd/C. However, by following the time courses of the hydrogenations, we found that the catalytic activity of the nanocatalyst (namely Pd CaROLig NPs) was much larger than that of Pd/C (Fig. 6), so that the reaction with Pd NPs reached quantitative conversion of 2-propen-1-ol within few hours. TEM images of the reaction mixture showed that the Pd NPs, while remaining spherical during the reaction, underwent extensive disaggregation, giving rise to many very small particles - less than $7 \mathrm{~nm}$ in diameter, to be compared with the 15-17 nm size of the initial NPs (Fig. 7) possibly responsible for the observed enhanced reactivity of the nanocatalyst.

In the hydrogenation of 2-buten-1-ol and 3-methyl-2-buten-1ol (cis/trans mix), conversions were strongly dependent upon the nature of the lignin employed, ranging from $23 \%$ to $80 \%$ and also selectivity was rather erratic, with the formation of all the possible products, i.e. of double bond hydrogenation (1-butanol

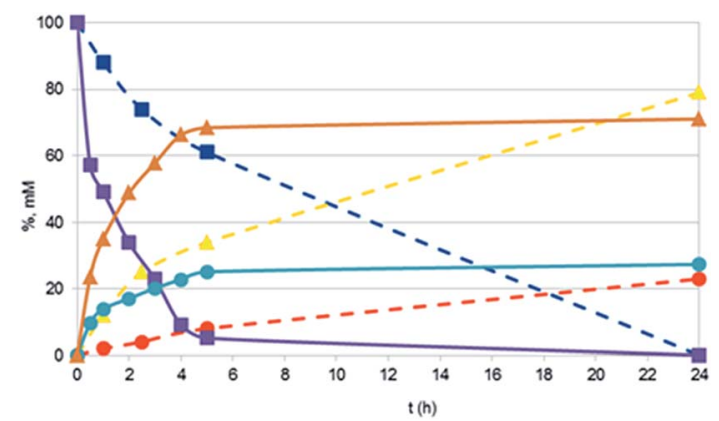

Fig. 6 Time course of 2-propen-1-ol hydrogenation by Pd/C (dashed lines) and Pd CaROLig NPs (solid lines): 2-propen-1-ol (squares); 1-propanol (circles); propanal (triangles). Reaction conditions, see Experimental. Data by ${ }^{1} \mathrm{H}$ NMR.

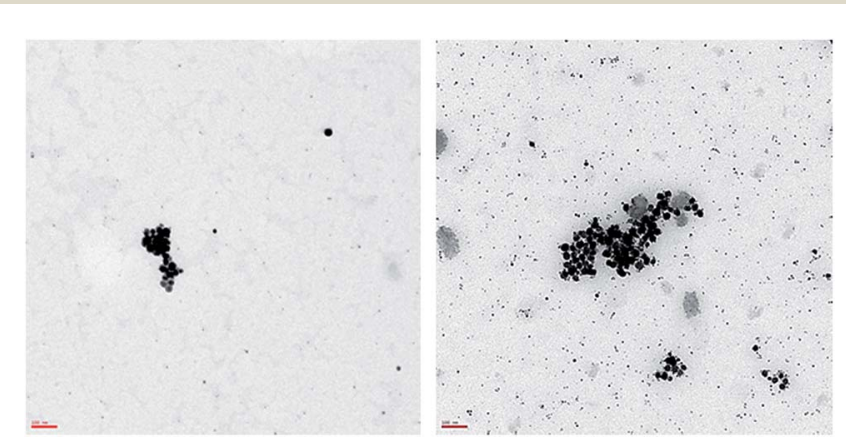

Fig. 7 TEM images of Pd AmLig NPs before (left, scale bar $=100 \mathrm{~nm}$ ) and after the hydrogenation reaction (right, scale bar $=100 \mathrm{~nm}$ ).

Table 3 Hydrogenation of allyl alcohols by Palladium catalysts ${ }^{a}$

\begin{tabular}{|c|c|c|c|c|c|}
\hline \multirow[b]{2}{*}{ Catalyst } & \multicolumn{5}{|l|}{ Substrate } \\
\hline & 2-Propen-1-ol & 2-Buten-1-ol & 3-Methyl-2-buten-1-ol & trans-2-Penten-1-ol & cis-2-Penten-1-ol \\
\hline Pd CaROLig NPs & $100(28,0,72)$ & $80(24,7,21,0)$ & $37(4,14,0,18)$ & $86(48,0,6,27)$ & $92(58,0,7,18)$ \\
\hline Pd AmLig NPs & $100(24,0,66)$ & $80(18,0,20,0)$ & $43(6,5,0,10)$ & $95(42,0,8,23)$ & $100(58,0,13,27)$ \\
\hline Pd KrLig NPs & $100(39,0,55)$ & $50(17,6,12,0)$ & $54(15,7,0,18)$ & $74(39,0,8,28)$ & $95(49,0,11,20)$ \\
\hline
\end{tabular}

${ }^{a}$ Conversions, \% (yields, \%: saturated alcohol, 2-unsaturated aldehyde, saturated aldehyde, 3-unsaturated alcohol), at $24 \mathrm{~h}$. Reaction conditions, see Experimental. Data by ${ }^{1} \mathrm{H}$ NMR and GC. Values are mean of three replicates; percent errors are always $<10 \%$. 
or 3-methylbutan-1-ol), of oxidative dehydrogenation (2-butenal or 3-methyl-2-butenal, up to $18 \%$; it should be noted that these products could not be detected in the first 6 hours of reaction), of isomerization (butanal, up to $21 \%$; 3-methylbutanal was not detected) and also of double bond migration (3-methyl-3butenol, up to $18 \%$; 3-butenol was not detected). Light hydrocarbons were never detected, nevertheless overall mass balances were largely unsatisfactory.

By contrast, the conversions of 2-penten-1-ols (both cis- and trans- isomers) were rather good, almost always quantitative, with 1-pentanol as the major product. Whereas pentenal was always absent and pentanal below 13\%, significant amounts of 3-penten-1-ol, arising upon double bond migration, were observed (10-37\%). Overall mass balances were generally satisfactory.

The isomerization pathway to the saturated aldehyde by $\mathrm{Pd}$ NPs was prevalent only for 2-propen-1-ol and less significant for the other examined substrates, in agreement with literature data reporting that the presence of C-sp ${ }^{2}$ substituents (methyl, ethyl, dimethyl versus hydrogen, in our case) generally depresses the selectivity toward carbonyl products, ${ }^{58}$ since the mechanism of the isomerization implies an hydrogen insertion into the terminal $\mathrm{C}-\mathrm{sp}^{2}$ and the formation of an enol, which tautomerizes to the corresponding carbonyl. ${ }^{50}$ Although isomerization of unsaturated alcohols to carbonyl derivatives is generally considered a minor reaction, in recent years highly selective processes have begun to attract growing interest. ${ }^{\mathbf{9 9 , 6 0}}$ Conversely, also the high yields of 1-pentanol from trans-2penten-1-ol could be of interest, in view of the poorer selectivities reported in the literature. ${ }^{58}$

\section{Conclusions}

All the examined metal NPs act as hydrogenation catalysts for allyl alcohols, albeit with very different yields and selectivities.

Broadly speaking, Pd NPs are far more catalytically active than the corresponding platinum-derivatives, but definitely favour the formation of saturated aldehydes over unsaturated alcohols, in line with the well-known reactivity of the conventional heterogeneous $\mathrm{Pd} / \mathrm{C}$ catalysts.

However, there are definite evidence that, during the reaction, the structure of the metal cores significantly modifies, giving rise to significant disaggregation (in the case of Pd NPs) or aggregation (in the case of Pt NPs) of the nanoparticles and therefore to more or less reactive species, respectively. In fact, Pd NPs, after the addition of fresh amounts of the substrate (i.e., 2-propen-1-ol) into the $24 \mathrm{~h}$ reaction mixture, continued to catalyze the reactions with same selectivity (although at a lower rate, $25 \%$ of conversion after $24 \mathrm{~h}$ ). In this case, it is possible that a structural change of lignin takes place, resulting in slowing down the passage of the substrate throughout the polymeric "protective shield" of the definitively smaller (and in principle more active) nanoparticles. Conversely, by adding fresh substrate into the Pt NPs reaction mixture, the reaction did not restart at all, likely because the observed extensive aggregation of NPs (Fig. 5) reduces the available metal surface area.
The nature of the lignins employed to stabilize the nanoparticles does not result in the formation of metal-cores very different in size; nevertheless, different lignins resulted in different reactivities of the obtained NPs, for both metals, although in a very obscure way. At the moment, we can only speculate that each one of the lignins employed (exhibiting different elemental compositions, in particular the $\mathrm{C} / \mathrm{O}$ ratios), may differ in polarity, degree of cross-linking and swallowability toward water, thus influencing the capability of the substrates to reach more or less easily the metal core.

Conversions of the various allyl alcohols, for both Pd and Pt NPs, generally follow the Lebedev rule, which establishes that the number of substituents attached to $\mathrm{C}-\mathrm{sp}^{2}$ atoms depresses the reactivity of the substrate versus hydrogen: ${ }^{61}$ indeed, the least substituted and least hindered substrate, i.e. 2-propen-1ol, is the most reactive and, generally speaking, the reactivity decreases from 2-propen-1-ol to 2-buten-1-ol and to 3-methyl-2buten-1-ol. However, 2-penten-1-ols exhibit a reactivity similar to the short-chain 2-propen-1-ol. Finally, Pd NPs were less selective than Pt NPs for the corresponding saturated alcohols, although with notable exceptions.

Although yields and conversions are not always satisfactory, when compared to those of the conventional heterogeneous catalysts, this study could be an important step aiming to design a "one-pot" reaction from glycerol, the natural feedstock from diesel production plants, to 1-propanol, an important commodity chemical. A preliminary test showed that: by purging continuously with hydrogen a 2,4-dimethyl-3-pentanol solution of glycerol and methyltrioxorhenium catalyst, collecting the gas phase (containing 2-propen-1-ol) in a cold water trap in the presence of catalytic amounts of Pt NaROLig NPs, 1-propanol can be obtained with high selectivity.

\section{Experimental}

\section{Materials}

Calcium lignosulphonates (CaLig), ammonium lignosulphonates (AmLig), sodium lignosulphonates (NaLig), calcium and sodium low-sugar lignosulphonates (CaRO and NaRO) were a gift from Burgo Group S.p.A. (Tolmezzo, Italy). Kraft lignin (KrLig) was purchased from Sigma-Aldrich. Chloroplatinic acid $\left(\mathrm{H}_{2} \mathrm{PtCl}_{6} \cdot 6 \mathrm{H}_{2} \mathrm{O}\right)$, and palladium chloride $\left(\mathrm{PdCl}_{2}\right)$ were purchased from Strem Chemicals. Deuterated 2-propen-1-ol-d $\mathrm{d}_{5}$ was prepared by literature. ${ }^{7}$ All the other remaining reagents were bought from Sigma-Aldrich. C, H, N and S elemental analyses of lignins were carried out by the 1106 Carlo-Erba Elemental Analysis (see Table 4).

\section{Synthesis and characterization of metal NPs}

Lignin stabilized Pd and Pt nanoparticles were prepared in accordance with our previous work. ${ }^{42}$ In brief, $0.06 \mathrm{~g}$ lignin were added to $0.03 \mathrm{~g} \mathrm{H}_{2} \mathrm{PtCl}_{6} \cdot 6 \mathrm{H}_{2} \mathrm{O}$ in $6 \mathrm{~mL}$ water or to $0.01 \mathrm{~g} \mathrm{PdCl}_{2}$ in $10 \mathrm{~mL}$ water. The solution was heated to $80{ }^{\circ} \mathrm{C}$ for $3 \mathrm{~h}$. The obtained NPs solution was used as such in the hydrogenation experiments. 
Table 4 Elemental analysis (C, H, N, S) of lignins used to prepare NPs

\begin{tabular}{lllll}
\hline & $\% \mathrm{C}$ & $\% \mathrm{H}$ & $\% \mathrm{~N}$ & $\% \mathrm{~S}$ \\
\hline KrLig & 61.47 & 5.71 & 0.68 & 1.47 \\
NaLig & 45.71 & 4.64 & 0.12 & 4.02 \\
CaROLig & 38.99 & 5.03 & 0.14 & 6.06 \\
AmLig & 41.72 & 5.19 & 3.57 & 7.48 \\
NaROLig & 39.89 & 5.00 & 0.15 & 5.88 \\
CaLig & 36.55 & 4.26 & 0.16 & 5.29 \\
& & & & \\
\hline
\end{tabular}

The nanoparticles were fully characterized with TEM, DLS, UV-vis, XRD and FT-IR. The UV-vis analyses were carried out in $1 \mathrm{~cm}$ quartz cuvettes (Hellma) by diluting $50 \mu \mathrm{L}$ of the NPs solution in $10 \mathrm{~mL}$ (for Pd) or $20 \mathrm{~mL}$ (for Pt) of ultrapure water. The UV-vis instrument was a Jenway 6505 spectrophotometer; with a spectral window range of $200 \mathrm{~nm}$ to $600 \mathrm{~nm}$.

The samples for Fourier transform infrared (FT-IR) spectroscopy were prepared by evaporating off the water solvent from the NPs. The resulting solid residue was milled with $\mathrm{KBr}(1 \%, \mathrm{w} / \mathrm{w})$ to form a very fine powder that was compressed into a thin pellet and analyzed using the FT-IR instrument (Perkin Elmer 1600), using a spectral window from $4000 \mathrm{~cm}^{-1}$ to $400 \mathrm{~cm}^{-1}$.

The samples for the TEM measurements were prepared by diluting $100 \mu \mathrm{L}$ of NPs solution in $10 \mathrm{~mL}$ water and placing it onto $3 \mathrm{~mm}, 300 \mathrm{mesh}$, formvar/carbon nickel grids (Agar Scientific Ltd), which were left drying in air at room temperature for $48 \mathrm{~h}$ to permit the evaporation of the solvent. The TEM measurements were performed under vacuum using a 109 Zeiss EM equipped with built-in electromagnetic objective lenses and a camera (Oberkochen, Germany).

For the DLS analyses, the samples were prepared by adding $200 \mu \mathrm{L}$ of the NPs solution in $1.8 \mathrm{~mL}$ of ultrapure water and put in a quartz cell for the acquisition. Experiments were performed on a Zetasizer Nano ZS, Malvern Instrument Ltd., U.K.

The samples for XRD analysis were prepared by solvent evaporation with rotary evaporator at $30^{\circ} \mathrm{C}$ of the $10 \mathrm{~mL}$ solution of Pd and Pt NPs and the resulting solid powder was placed on the glass plate of the instrument. The XRD analysis was performed on a Miniflex II Rigaku automated power XRD system (Cu K $\alpha$ radiation, $45 \mathrm{kV}, 100 \mathrm{~mA}$ ) (RINT 2500, Japan). Diffraction data were recorded using continuous scanning at $3^{\circ}$ $\min ^{-1}$, with $0.010^{\circ}$ steps and a PDF-4/mineral 2013 database.

GC analyses were performed on an HP 68970 GLC instrument equipped with a FID, using a $30 \mathrm{~m}$ HP-5 capillary column (0.32 mm i.d.; 0.25 film thick) with the injection port kept at $250{ }^{\circ} \mathrm{C}$ (carrier gas: $\mathrm{He}$ ).

The gas chromatography-mass spectroscopy (GC-MS) apparatus comprised a Thermo Scientific Focus series gaschromatograph coupled to an ISQ mass-selective detector equipped with a split/splitless injection system (injections made in split mode) and an HP-5 MS (cross-linked 5\% phenyl methyl siloxane) capillary column (30 m length, $0.25 \mathrm{~mm}$ diameter, $0.1 \mu \mathrm{m}$ film thickness) using helium as carrier gas at constant pressure of $30 \mathrm{kPa}$. The acquisition parameters were: source at $250{ }^{\circ} \mathrm{C}$, transfer line at $250{ }^{\circ} \mathrm{C}, 3 \mathrm{~min}$ of delay acquisition time at the beginning of the analysis, mass range 33-350 amu, injector temperature $250{ }^{\circ} \mathrm{C}$, initial temperature of the analyses $60{ }^{\circ} \mathrm{C}(1 \mathrm{~min})$, then $10^{\circ} \mathrm{C} \mathrm{min}^{-1}$ up to $250{ }^{\circ} \mathrm{C}$ (kept for $6 \mathrm{~min}$ ), for a total acquisition time of $26 \mathrm{~min}$. The sample injected was $1 \mu \mathrm{L}$.

NMR spectra were obtained using a Bruker Avance 300 spectrometer (7.05 Tesla) equipped with a high resolution multinuclear probe that operated in the range of $30 \mathrm{MHz}$ to 300 MHz. To eliminate the dominant water signal in the ${ }^{1} \mathrm{H}$ NMR spectra, water suppression was carried out using a presaturation sequence of a composite pulse (zgcppr Bruker sequence). A co-axial capillary tube that contained a $30 \mathrm{mM} \mathrm{D}_{2} \mathrm{O}$ solution of 3-(trimethylsilyl) propionic-2,2,3,3- $\mathrm{d}_{4}$ acid, sodium salt, was used as the reference.

\section{Hydrogenation procedure}

$15 \mathrm{~mL}$ of deionized water was placed into an hermetically closed $20 \mathrm{~mL}$ vial and then $100 \mu \mathrm{L}$ of Pd NPs $(0.56 \mu \mathrm{mol} \mathrm{Pd} ; 0.04 \mathrm{mmol}$ $\mathrm{Pd} / \mathrm{L}$ solution) or $100 \mu \mathrm{L}$ of Pt NPs $(0.97 \mu \mathrm{mol} \mathrm{Pt}$; $0.07 \mathrm{mmol} \mathrm{Pt} / \mathrm{L}$ solution) solution were introduced; the mixture was fluxed bubbling hydrogen gas for 20 minutes. The substrate (0.3 mmol; $20 \mathrm{mM}$ ) was added. The reaction solution was left under static $\mathrm{H}_{2}$ atmosphere at room pressure (1.013 barr) and temperature $\left(20^{\circ} \mathrm{C}\right)$ and stirred for $24 \mathrm{~h}$.

In the reactions catalyzed with commercial $\mathrm{Pt} / \mathrm{C}$ and $\mathrm{Pd} / \mathrm{C}$, we used $1 \mathrm{mg}$ of $10 \% \mathrm{Pd} / \mathrm{C}(0.9 \mu \mathrm{mol} ; 0.06 \mathrm{mmol} \mathrm{Pd} / \mathrm{L}$ solution) or $4 \mathrm{mg}$ of $5 \% \mathrm{Pt} / \mathrm{C}(1 \mu \mathrm{mol} ; 0.07 \mathrm{mmol} \mathrm{Pt} / \mathrm{L}$ solution $)$ in $15 \mathrm{~mL}$ of water and in presence of $0.3 \mathrm{mmol}$ of allyl alcohol (20 $\mathrm{mM})$.

In a preliminary test, a 2,4-dimethyl-3-pentanol solution $(5 \mathrm{~mL})$ of glycerol $(5 \mathrm{mmol})$ and methyltrioxorhenium catalyst (0.1 mmol) held at $140{ }^{\circ} \mathrm{C}$ was purged continuously with hydrogen and the gas phase, which contained 2-propen-1-ol, was collected in a cold water trap $(100 \mathrm{~mL})$ in the presence of Pt NaROLig NPs catalyst ( $5 \mu \mathrm{mol}$ of Pt), producing 1-propanol.

\section{Acknowledgements}

We thank "Consorzio di Ricerca per l'Innovazione Tecnologica, la Qualità e la Sicurezza degli Alimenti S.c.r.l.” (CIPE funding 20.12.04; DM 28497) and the "Ministero dell'Istruzione, dell'Università e della Ricerca” (MIUR) for financial support.

\section{References}

1 M. Lapuerta, J. Rodríguez-Fernandez, R. García-Contreras and M. Bogarra, Fuel, 2015, 139, 171.

2 W. Tutak, K. Lukács, S. Szwaja and Á. Bereczky, Fuel, 2015, 154, 196.

3 Y. Gu, Y. Jiang, H. Wu, X. Liu, Z. Li, J. Li, H. Xiao, Z. Shen, H. Dong, Y. Yang, Y. Li, W. Jiang and S. Yang, Biotechnol. J., 2011, 6, 1348.

4 E. N. Efremenko, N. A. Stepanov, A. B. Nikolskaya, O. V. Senko, O. V. Spiricheva and S. D. Varfolomeev, Catal. Ind., 2011, 3, 41. 
5 K. Liu, H. K. Atiyeh, O. Pardo-Planas, T. C. Ezeji, V. Ujor, J. C. Overton, K. Berning, M. R. Wilkins and R. S. Tanner, Bioresour. Technol., 2015, 189, 292.

6 S. Atsumi, T. Hanai and J. C. Liao, Nature, 2008, 451, 86.

7 V. Canale, L. Tonucci, M. Bressan and N. d'Alessandro, Catal. Sci. Technol., 2014, 4, 3697.

8 D. Taher, M. E. Thibault, D. Di Mondo, M. Jennings and M. Schlaf, Chem.-Eur. J., 2009, 15, 10132.

9 M. E. Thibault, D. V. DiMondo, M. Jennings, P. V. Abdelnur, M. N. Eberlin and M. Schlaf, Green Chem., 2011, 13, 357.

10 M. Steffan, F. Klasovsky, J. Arras, C. Roth, J. Radnik, H. Hofmeister and P. Claus, Adv. Synth. Catal., 2008, 350, 1337.

11 S. Di Dio, M. Marchetti, S. Paganelli and O. Piccolo, Appl. Catal., A, 2011, 399, 205.

12 S. De, B. Saha and R. Luque, Bioresour. Technol., 2015, 178, 108.

13 A. B. Bindwal and P. D. Vaidya, Energy Fuels, 2014, 28, 3357. 14 E. Falabella Sousa-Aguiar, L. Gorenstin Appel, P. Costa Zonetti, A. do Couto Fraga, A. Azevedo Bicudo and I. Fonseca, Catal. Today, 2014, 234, 13.

15 R. Ciriminna, V. Pandarus, F. Béland and M. Pagliaro, Org. Process Res. Dev., 2014, 18, 1110.

16 E. L. Kunkes, D. A. Simonetti, R. M. West, J. C. Serrano-Ruiz, C. A. Gärtner and J. A. Dumesic, Science, 2008, 322, 417.

17 H. Oyamada, T. Naito, S. Miyamoto, R. Akiyama, H. Hagioa and S. Kobayashi, Org. Biomol. Chem., 2008, 6, 61.

18 A. F. Barrero, E. J. Alvarez-Manzaneda, R. Chahboun and R. Meneses, Synlett, 1999, 10, 1663.

19 R. A. W. Johnstone, J.-Y. Liu, L. Lu and D. Whittaker, J. Mol. Catal. A: Chem., 2003, 191, 289.

20 L. Huang, P. Luo, W. Pei, X. Liu, Y. Wang, J. Wang, W. Xing and J. Huang, Adv. Synth. Catal., 2012, 354, 2689.

$21 \mathrm{X} . \mathrm{Xu}, \mathrm{H}$. Li and Y. Wang, ChemCatChem, 2014, 6, 3328.

22 P. Claus, Top. Catal., 1998, 5, 51.

23 P. Mäki-Arvela, J. Hájek, T. Salmi and D. Yu Murzin, Appl. Catal., A, 2005, 292, 1.

24 P. Claus and Y. Önal, in Handbook of Heterogeneous Catalysis, ed. G. Ertl, H. Knözinger, F. Schüth and J. Weitkamp, WileyVCH, Weinheim, 2008.

25 V. Ponec, Appl. Catal., A, 1997, 149, 27.

26 P. Gallezot and D. Richard, Catal. Rev.: Sci. Eng., 1998, 40, 81. 27 Y. Dai, Y. Wang, B. Liu and Y. Yang, Small, 2015, 11, 268.

28 Z. Guan, S. Lu and C. Li, J. Catal., 2014, 311, 1.

29 S. Mandal, D. Roy, R. V. Chaudhari and M. Sastry, Chem. Mater., 2004, 16, 3714.

30 S. Bhattacharjee and M. L. Bruening, Langmuir, 2008, 24, 2916.

31 J. Liu, X. Liao and B. Shi, Res. Chem. Intermed., 2014, 40, 249. 32 R. Bhandari, D. B. Pacardo, N. M. Bedford, R. R. Naik and M. R. Knecht, J. Phys. Chem. C, 2013, 117, 18053.

33 D. J. Gavia, M. S. Maung and Y.-S. Shon, ACS Appl. Mater. Interfaces, 2013, 5, 12432.

34 Y. Jiang and Q. Gao, J. Am. Chem. Soc., 2006, 128, 716.
35 C. Ornelas, J. R. Aranzaes, L. Salmon and D. Astruc, Chem.Eur. J., 2008, 14, 50.

36 F. Iram, M. S. Iqbal, M. M. Athar, M. Z. Saeed, A. Yasmeen and R. Ahmad, Carbohydr. Polym., 2014, 104, 29.

37 M. Sayeed Akhtar, J. Panwar and Y.-S. Yun, ACS Sustainable Chem. Eng., 2013, 1, 591.

38 W. Chen, L. Zhong, X. Peng, J. Lin and R. Sun, Cellulose, 2014, 21, 125.

39 M. Khan, M. Khan, M. Kuniyil, S. F. Adil, A. Al-Warthan, H. Z. Alkhathlan, W. Tremel, M. N. Tahir and M. R. H. Siddiqui, Dalton Trans., 2014, 43, 9026.

40 J. Mittal, A. Batra, A. Singh and M. M. Sharma, Adv. Nat. Sci.: Nanosci. Nanotechnol., 2014, 5, 043002.

41 M. J. Rak, T. Friščić and A. Moores, Faraday Discuss., 2014, 170, 155.

42 F. Coccia, L. Tonucci, D. Bosco, M. Bressan and N. d'Alessandro, Green Chem., 2012, 14, 1073.

43 F. Coccia, L. Tonucci, N. d'Alessandro, P. D'Ambrosio and M. Bressan, Inorg. Chim. Acta, 2013, 399, 12.

44 S. K. Maity, Renewable Sustainable Energy Rev., 2015, 43, 1427.

45 S. K. Maity, Renewable Sustainable Energy Rev., 2015, 43, 1446.

46 S. Navaladian, B. Viswanathan, T. K. Varadarajan and R. P. Viswanath, Nanoscale Res. Lett., 2009, 4, 181.

47 H. Tong, H.-L. Li and X.-G. Zhang, Carbon, 2007, 45, 2424.

48 D. H. Leung, R. G. Bergman and K. N. Raymond, J. Am. Chem. Soc., 2007, 129, 2746.

49 M. G. Musolino, C. V. Caia, F. Mauriello and R. Pietropaolo, Appl. Catal., A, 2010, 390, 141.

50 E. Sadeghmoghaddam, K. Gaïeb and Y.-S. Shon, Appl. Catal., A, 2011, 405, 137.

51 R. Hubaut and J. P. Bonnelle, React. Kinet. Catal. Lett., 1992, 47, 73.

52 C. Hoang-Van and O. Zegaoui, Appl. Catal., A, 1997, 164, 91.

53 H. Wei, C. Gomez, J. Liu, N. Guo, T. Wu, R. Lobo-Lapidus, C. L. Marshall, J. T. Miller and R. J. Meyer, J. Catal., 2013, 298, 18.

54 M. Imachi, N. W. Cant and R. L. Kuczkowski, J. Catal., 1982, $75,404$.

55 C. Keresszegi, T. Mallat and A. Baiker, New J. Chem., 2001, 25, 1163.

56 J. Guerra, J. L. Burt, D. A. Ferrer, S. Mejía and M. JoséYacamán, J. Nanopart. Res., 2011, 13, 1723.

57 H. Pines, The Chemistry of Catalytic Hydrocarbon Conversions, Academic Press, Inc., New York, USA, 1981.

58 M. G. Musolino, P. De Maio, A. Donato and R. Pietropaolo, J. Mol. Catal. A: Chem., 2004, 208, 219.

59 S. Gargiulo, D. J. Opperman, U. Hanefeld, I. W. C. E. Arends and F. Hollmann, Chem. Commun., 2012, 48, 6630.

60 M. Moreno, L. N. Kissell, J. B. Jasinski and F. P. Zamborini, ACS Catal., 2012, 2, 2602.

61 S. V. Lebedev, G. G. Kobliansky and A. O. Yakubchik, J. Chem. Soc., Trans., 1925, 127, 417. 